\title{
Complex sociotechnical systems as a subject of constructivist epistemology research: a descriptor of subjectivity
}

\author{
Igor Korotets ${ }^{1, *}$, Tat'yana Podshibyakina ${ }^{1}$ and Alexandr Fedoseenkov ${ }^{2}$ \\ ${ }^{1}$ Department of theoretical and applied political science, Southern Federal University (SFU), 344006 \\ Rostov-on-Don, Russia \\ ${ }^{2} \mathrm{Ph} . \mathrm{D}$ in Philosophy, Associate Professor of the Department of Philosophy and World Religions, Don \\ State Technical University (DSTU), 344002 Rostov-on-Don, Russia.
}

\begin{abstract}
Epistemology began to show some signs of crisis, it touched its scientific paradigm: the object. subject, method, as well as its social relevance. In society, there was a request not only to obtain knowledge about knowledge, but also to use knowledge management technologies as a consumer of information, which is due to the rapid growth of the number of Internet users and its autonomy and independence. The aim of the work is to consider in the subject field of epistemology of technical networks (Internet) as an independent actor and an element of a special sociotechnical system; analysis of the activities of network social actors to establish control over the process of social cognition through knowledge management and attitudes. Bruno Latour's "actor-network theory" (ANT) was chosen as the research method it allows to give theoretical and methodological substantiation of the descriptor of subjectivity of networks in complex sociotechnical systems. The paper assesses the technical networks (Internet) as an independent actor of the sociotechnical system and describes their functioning in this capacity. The analysis of such a sphere in the subject area of epistemology as knowledge management, little studied, but extremely relevant in connection with the perception of the global Internet as a fairly independent area of life of network communities and new network media. It is concluded that a promising direction for modern constructivist epistemology is the study of the problems of establishing control over the production, transfer and accumulation of knowledge in society, as well as the negative manifestations of such control in the form of manipulation of consciousness, the use of open and hidden censorship.
\end{abstract}

\section{Introduction}

Epistemology is currently in search of new scientific paradigms that would allow it to meet the modern demands of society for knowledge related to everyday practices. Critics of epistemology argue that problems traditionally included in the subject area of epistemology

\footnotetext{
${ }^{1}$ Corresponding author: tan5@bk.ru
} 
should be studied by means of special Sciences of knowledge. One such science that can breathe "second life" into epistemology is cognitive science, which has developed under the influence of cognitive psychology, psychophysiology, neurophysiology, Cybernetics, cognitive linguistics and considers cognition as a continuous process of information processing. Thus, the philosophical analysis of knowledge as an element of the process of cognition can be put at the service of everyday cognitive practices.

The deepening of knowledge into the sphere of essence led to the emergence in the scientific space of systems adequate to the object of knowledge. This adequacy means the translation of the cognitive image into a material object, for example, in $3 \mathrm{~d}$ technology. Such cognitive-technological achievements can be interpreted as a fundamental change in the system of interaction between practice and knowledge. In addition, the whole system of cognition becomes alternative, creating conditions for variability not only mental structures, but also objectivity. Practically objective reality, which was the basis of the theory of knowledge in the system of materialism, acquired the status of relativity and became a transient element of the holistic system. Just as in the modern economy, consumption rather than production becomes the dominant element, in the knowledge-practice system, knowledge comes first. In the network space, the priority position is occupied by knowledge about knowledge, i.e. knowledge management (M. Castels).

\section{Problem statement}

Many see the way out of the crisis of epistemology as a scientific direction in the development of various forms of modern epistemological constructivism, in particular the empirical constructivism of Bruno Latour (Kasavin, Porus, 2018) and his "actor-network theory" (Latour, 2005), which develops the ideas of "social constructivism" of Berger and Lukman. The main philosophical question of epistemological constructivism is the relation of cognitive constructions to reality and whether it is a product of cognition.

The problem of updating epistemology is partly related to the changes that occur in the subject of its study. The advent of new technologies has significantly changed the way knowledge is acquired and beliefs are justified. It has been suggested in the scientific community that philosophers, and especially epistemologists, should participate in contemporary discussions about these changes. "Knowledge economy "and" information society " require a new approach to epistemology (Coady, 2016). The most promising area of research should be the problems of knowledge management and the emergence of " circles of control, effectively describing the scope of possible actions of the individual in certain situations (Berger, Lukman, 1995).

The aim of the work is to consider in the subject field of epistemology of technical networks (Internet) as an independent actor and an element of a special sociotechnical system; to analyze the activities of various network social actors to establish "control over the process of social cognition through fine management of knowledge and attitudes" (T. van Dyck).

\section{Method of research}

Bruno Latour's "actor-network theory" (ANT) was chosen as the research method.it allows to give theoretical and methodological substantiation of subjectivity descriptor in complex sociotechnical systems. ANT is a method in which the network has "a connected series of actions, each participant of which is treated as a full-fledged intermediary". The concept of "actor-network" is used by La tour as the main analytical tool of the study. "Actor" is not considered as a source of meaningful action, it can be "anything that changes the status quo 
that creates a difference" Thing can provide an opportunity to promote or limit, allow, guide, hinder, stop. An actor is an intermediary who encourages other actors to act. Bruno Latour rejects the approach of the object (Latour, B., \& Davis, L., 2019) as "inert and passively circulating among networks of practices, institutions, and historical events." The "actornetwork theory" (ANT) also has opponents, such as David Bloor, who questions the novelty of the theory, accuses Latour of being uncritical about the problem of relativism and realism in relation to the arguments of the actors themselves.

\section{Cases and their analysis}

The descriptor of subjectivity is supposed to be considered on the example of the case of technical networks (Internet), for this purpose it is required to evaluate them as an independent actor and describe the ways of functioning. And yet the question is legitimate: can the Internet be considered as an actor-network, and therefore can it have a sign of subjectivity? In relativistic theory there is an epistemological myth of the "external observer". According to Latour, in order to explain, consider, observe, prove, assert, dominate and see, he (the observer) must move and work, or "build networks". Technical networks are only a special case of actor networks (Latur, 2017).

W. Lance Bennett \& Alexandra Segerberg (2012), using Latour's theory investigated the "organizational structure of people and social technologies", proposed to recognize the mechanisms of digital networks (for example, various social networks and devices that control them) as potential network agents along with people (for example, individuals and organizations). Such Facebook Facebook digital mechanisms may include: organizational connectors (such as web links), event coordination (such as protest calendars), information sharing (such as YouTube and Facebook), and multi-functional networking platforms that other networks are embedded in (such as links in Twitter and Facebook posts).

Another social actor of the Internet is the structures of knowledge communities and, in particular, the organizations of "epistemic communities", or groups of agents sharing common knowledge problems. Their interactions are usually based on either social relationships or semantic similarities. Epistemic communities are quite influential, they even participate in the formation of global society through the construction of (world) politics.

Epistemology is still a Central component of the philosophy of information. At present, a very promising question for studying as a subject of epistemology at the level of network practices is: "How do you know?". Studies show that knowledge acquisition cannot be carried out by users without the impact of applied technologies on their selection criteria (Fallis, \& Whitcomb, 2009). How can social networks, viewed as an independent entity, influence the formation of knowledge among network users? The effect of echo chambers and filter bubbles has been well studied in the research literature (Borra, \& Weber, 2012). The emergence of echo chamber effects (Sunstein) and filter bubbles (Pariser), which are an obstacle to the reception of knowledge, has led to the growing polarization of discourse, combined with online cultures offering the availability of information about what likeminded people think about it, in the literature there are different points of view on the characterization of the echo chamber effect (Wagner, \& Ylä-Anttila, 2018). Wagner, Paul M., and Tuomas Ylä-Anttila are among those researchers who believe that people and organizations tend to get information from those whose beliefs are similar to their own, forming "echo chambers" with their network connections. The effect of echo chambers has also been compared to epistemic circles and networks (Madsen, 2018), where like-minded people actively communicate and become increasingly entrenched in their beliefs.

Implicit forms of censorship in the network space are aimed at weakening basic cognitive abilities such as attention, coherent thinking and memory. This kind of censorship can be called cognitive, attributed to the varieties of "mental control", which is carried out by 
symbolic elites through the choice of certain " genres, themes, arguments, style, rhetoric and presentation of public discourse "(T. van Dyck). The main strategies used in the media space are falsification, absurdization and hoax. I would especially like to note the prospects for the development of such a sphere of the subject area of epistemology as knowledge management, little studied, but extremely relevant in connection with the perception of the global Internet as a fairly Autonomous area of life of network communities and new network media.

The problems of establishing control over the production, transfer and accumulation of knowledge in the social context, as well as the negative manifestations of such control in the form of manipulation, the establishment of open and hidden censorship, are practically not studied now. Overcoming the crisis of epistemology in the end, perhaps, is associated with a change in the scientific paradigm.

\section{Conclusion}

In conclusion, I would like to assess the possible promising directions of epistemology development, determined by the changes taking place in its subject area and associated with the intensive development of Internet technologies and social effects of their application.

Epistemology, focusing on reality, should use all the resources of the constructivist direction, both empirical and social; consider as a subject of research the results of constructivist activities of subjects in the form of social practices.

The methodology of epistemological research should adapt methods that allow analyzing complex sociotechnical systems in their integrity and in the aggregate interaction of actors of the material and non-material sphere.

I would especially like to note the prospects for the development of such a sphere of the subject area of epistemology as knowledge management, little studied, but extremely relevant in connection with the perception of the global Internet as a fairly Autonomous area of life of network communities and new network media.

The problems of establishing control over the production, transfer and accumulation of knowledge in the social context, as well as the negative manifestations of such control in the form of manipulation, the establishment of open and hidden censorship, are practically not studied now. Overcoming the crisis of epistemology in the end, perhaps, is associated with a change in the scientific paradigm.

The study was carried out with the financial support of The Russian Foundation for basic research No. 19-011-31284 OPN.

\section{References}

1. E. Borra, I Weber, Political Insights: Exploring partisanship in Web search queries, F. Mon., 17 (7) (2012).

2. W. L. Bennett, A. Segerberg, The logic of connective action: Digital media and the personalization of contentious politics, Info., commun. \& soc., 15 (5), 739-768 (2012).

3. P. Berger, T. Lukman, Social'oye konstruirovanie real'nosti, Traktat po sociologii znanija (1995).

4. D. Blur, Anti-Latur, Log. J., 27 (1) (2017).

I. T. Kasavin, V. N. Porus, Sovremennaya epistemologiya $i$ ee kritiki: o krizisah $i$ perspektivah, Epistem. \& Phil. of Sc., 55 (4) 15 (2018).

5. D. Coady, Applied Epistemology, A Comp. to Appl. Phil. (2016). 
6. B. Latour, Reassembling the Social: An Introduction to Actornetwork-Theory, Clarendon Lect. in Man. St. (2005).

7. B. Latur, Ob aktorno-setevoj teorii. Nekotorye raz'yasneniya, dopolnennye eshche bol'shimi uslozhneniyami, Log. J., 27 (1) (2017).

8. B. Latour, L. Davis, Do Scientific Objects Have a History? Pasteur and Whitehead, Bath of Lactic Acid. Com. Knl., 25 (1), 126-142 (2019).

9. J. K. Madsen, R. M. Bailey, T. D. Pilditch, Large networks of rational agents form persistent echo chambers, Sc. Rep., 8 (1), 12391 (2018).

10. P. M. Wagner, T. Ylä-Anttila, Policy forums Can overcome the echo chamber effects by enabling policy learning? Evidence from the Irish climate change policy network. J. of Pub. Pol., 1-18 (2018). 